\title{
Mathematics and Metaphor
}

\author{
A Response to Elizabeth Mowat \& Brent Davis
}

\section{PAUL ERNEST \\ University of Exeter (UK)}

Mathematics is weird and wonderful, and all of us who work with and around it have a contradictory nexus of feelings of fascination, love and hate. Mathematics is the stern parent we love and want approval from but expresses so little emotion. Mathematics is the cold implacable icy wall that resists our finger holds and keeps us out (Buerk 1982). Mathematics is the cerebral zone we break into and wonder at the beautiful crystalline forms that stretch off to infinity in richly etched exquisiteness. Mathematics is that hot passionate moment when the links we are working so hard to forge twist into place and the chains all mesh and glint together in a perfectly symmetric whole. Mathematics is that golden vision of perfect form we bathe in after the years of meditative discipline fall into place leaving us speechless and egoless in wonder. Mathematics is the vision of god that strikes awe into the heart of the unbeliever but still allows her/him to be an atheist.

So how do we react to these ineffable encounters? We try to describe, capture, tame, label, structure, define mathematics. My tentative poetic descriptions and metaphors presented above are more of this same. So many of us build visions of mathematics that we want to share with others. Maybe I have been doing nothing but this all my professional life. Perhaps that is why when I travel through other people's visions I struggle to keep my own visions alive and won't succumb to theirs.

I am responding to a piece that is structured around two main metaphors for mathematics. The first is networks or complex systems. The second is embodiment as the source of mathematical meaning via metaphor. Both are rich and respectable images 
for mathematics, but I want to argue with them, especially the second, pointing to the corners that don't work. Why? Mathematics teaches one to be cautious in accepting generalizations and always to look for counter-examples. I suppose the question should not be the one I always succumb to: "does it satisfy me?" but rather "what new insights does it shed on the practices of the teaching and learning of mathematics?" Maybe there are good answers waiting in the wings for this latter question. Some of them are prefigured in the paper to which I am responding.

The claim that mathematics is a complex system is valuable. Mathematics truly has many elements. Indeed, as is acknowledged, the very term "mathematics" is highly ambiguous. Mathematics is an organised body of knowledge, a practice engaged in by mathematicians, a school subject, a cultural object of many meanings, and a language and box of conceptual tools used variously in many different practices. Its name alone (mathematics) is ambiguous because it is a plural word that is treated as naming a single entity. Wittgenstein (1978) acknowledged this multiplicity in referring to the "motley of mathematics" (p. 182). Treating mathematics as a complex system is a way of dealing with this.

Some nice examples are given of conceptual maps for subjective mathematical understanding, one for the idea of circle, and another for that of container. What is nice about these is the richness of connections with nodes in many modalities including conceptual, tactile, auditory, emotional, kinesthetic, lexical, spatial logic, and visual. No claim is made for the completeness of this list, they are merely the salient features in the examples given. We could even expand the range of possible registers to include heard/spoken language, written language, and symbolic representations, both alphanumeric and pictogrammatic. The notion that mathematical ideas form complex interconnected networks is, not surprisingly, a rich one. The sub-networks illustrated are just foregrounded parts of a much larger, multiply realized, emergent and emerging set of webs. Such a model supports a move away from the predominance of hierarchies in learning, such as Piaget's stage theory, that proposes a strict sequence of stages that a learner's development must go through. Instead it sees the teaching and learning of mathematics and the resultant complex of ideas as an interconnected network of concepts, representations, memories, etc. This distinction is mirrored in Deleuze and Guattari's (2007) contrast between the tracing and the map.

A "tracing" is like a tree because it grows by reproducing the same pattern in its branches and leaves. On the other hand, a "map" is in a constant state of flux; a "map is open and connectable in all its dimensions; it is detachable, reversible, susceptible to constant modification" (Deleuze \& Guattari, 2007, p. 12). Whilst tracings represent structures that get reproduced by repetition like a genetic code, maps are rhizomes that increase their power by increasing their connections. According to Deleuze and Guattari (2007), mathematics resists tracing: Like a map, it is open-ended and teeming with connections. Gracefully put, the learner of school mathematics is immersed in an expansive language, which unfolds like a map beckoning towards new territories. Though it is true that every human language, mathematics included, is invented by people and is meaningless without the company of some lived activity, the experience of exploring the "map" is, to me, an aesthetic state of "becoming." (Browne 2009: 11-12) 
The networks or webs illustrated in the chapter are maps or rhizomes in this sense, with all the entailed flux and emergent connections and new nodes.

The second theme of the paper is embodiment as the source of mathematical meaning via metaphor. In effect, this is a proposal to impose a master metaphor: all human activity (including mathematical doing and learning) is human bodily movement. Now this claim should be clarified, for the identity asserted is not literal as in, e.g., the claim that simplifying an algebraic equation is a bodily movement, but rather that the basic meaning underpinning simplifying an algebraic equation is based on bodily movement. Indeed, it is possible to argue plausibly that the basic meaning of the equals sign, the central binary predicate that relates two terms in an identity, is based on the bodily metaphor of balance. Two weights in the pans of a set of scales only balance when they are equal in weight, and this can be felt bodily in the forces on supporting hands under the pans. It can be felt when we are physically unbalanced, and feel the pull to one side or the other. Operations in solving equations only work if they act equally on both sides of the balance, i.e., maintain the identity.

I have argued elsewhere that mathematical activity can be seen in terms of sign operations within semiotic systems. A semiotic system is made up of three components: A set of signs; A set of rules for sign use and production; An underlying meaning structure, incorporating a set of relationships between these signs and rules. Thus a sign system for elementary algebra, the metaphor of balance is present in the meaning structure underpinning the meaning of the sign " $=$ ", and the rules for operating on it (e.g., reflexivity, symmetry, transitivity). (see also Ernest 2006, 2008). In such a system, the seat of metaphor, and meanings more generally, is to be found in the underlying meaning structure, itself a network.

The enactivity principle is not new in education. Bruner (1964) tried to reconcile the works of C. S. Peirce (1931-58) and J. Piaget when he came up with his theory of the spiral curriculum. According to this theory, concepts and topics in mathematics (and elsewhere) should be taught through a sequence of modes of representations: enactive, iconic, symbolic. The idea is that enactive bodily experiences are the deepest and best understood and retained. Visual experiences are well understood. In contrast symbolic knowledge is the least immediate of these three and the easiest to forget. This idea is expressed in an ancient Chinese proverb "I hear and I forget, I see and I remember, I do and I understand", that was adopted by the Nuffield Mathematics Teaching Project (1965) in the 1960s. Figure 1 illustrates Bruner's ideas with respect to two mathematical concepts, namely fraction and reflection.

Figure 1 illustrates how the concept of fraction can be introduced enactively, through such bodily actions as cutting a cake into $1 / 6^{\text {ths }}$, or by sharing out 6 sweets among 6 children. Similarly the concept of reflection can be introduced by manipulating a mirror or by cutting out faces in a folded sheet of paper. It also shows how these concepts can be represented iconically, through the use of a variety of pictorial representations of the fraction $1 / 6^{\text {th }}$ and through the use of a "mirror line" in a drawing for constructing the reflection of a pictorial shape. 


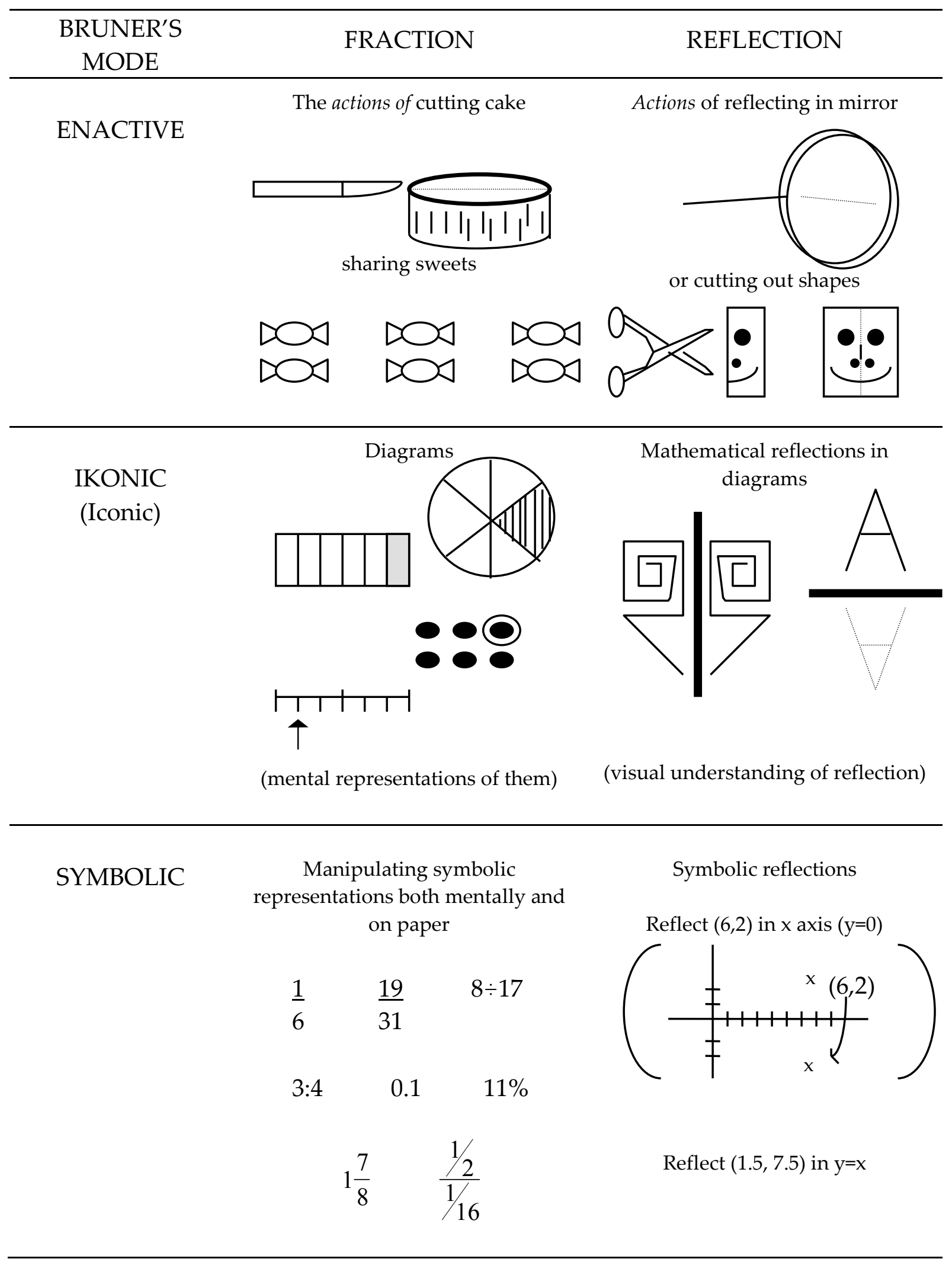

Figure 1: Activities representing fractions and reflection in Bruner's three modes. 
Lastly the figure shows examples of symbolic representations of the two concepts. This includes some of the many ways of representing fractions or rational numbers symbolically, as used in school mathematics, as well as symbolic representations of reflections utilizing the Cartesian coordinate system. Bruner uses Peirce's ideas of sign in conjunction with Piaget's stage theory, with the sensori-motor and pre-operational stages more or less corresponding to enactive representation; the stage of concrete operations corresponding to iconic representation, and the stage of formal operations corresponding to symbolic representation. However, unlike Piaget, Bruner does not tie his stages to children's ages, but argues that the introduction to, or elaboration of, any mathematical concept following his spiral curriculum model should utilize the representational sequence enactive-iconic-symbolic at any age.

Although Bruner utilized the ideas of Peirce in his theory he sacrificed some of the original distinctions for educational purposes. In fact Peirce offers a triadic analysis of signs made up of icon, index and symbol. First of all, an icon is a sign that incorporates some of the meaning or structure of what it represents (like a Russian Icon). Many communicative bodily gestures, as well as pictograms, diagrams, and onomatopoeic words all fall under his category of icon. Thus it encompasses both of Bruner's enactive and iconic modes. Secondly, an index is a sign that indicates its referent through pointing (like an index finger) or proximity, i.e., via presence with spatio-temporal contiguity. This category is ignored by Bruner in his quest for an educative sequence. Thirdly, a symbol is an arbitrary designation of its referent.

The form of enactivism endorsed in the paper I am responding to proposes that bodily metaphor is the fundamental form serving as the basis for other forms of meaning. However, this is just one part of iconic representation. Peirce's iconic mode incorporates all forms of metaphor and analogy, substantially exceeding the bodily metaphors prioritized by Lakoff and Núñez (2000) as the basis for mathematics. It can also be said that not all enactive movements serving as communicative gestures are strictly based on bodily metaphors. One of the fundamental designators of meaning or significance is finger pointing, and this falls into Peirce's class of indexical signs. This distinction is important and Jakobson (1956) and others distinguish two fundamental modes of designating meaning in language beyond the literal, namely metaphor and metonymy. While metaphor is based on the similarity of a sign and its referent, metonymy works by the contiguity of a sign with its referent, that is, their proximity or association in time or space. Thus a pointing finger, a canonical example of Peirce's indexical sign, is a bodily gesture working by metonymy, indicating a proximate referent through line of sight. Thus just as not all metaphors can be captured by bodily movements, so too not all bodily movements serving as signs function through metaphor.

To argue that bodily movement serves as the metaphorical base for all mathematical concepts, as Lakoff and Núñez (2000) do, is to stretch the underlying insight too far. Undoubtedly bodily movements and bodily experiences do provide fundamental meanings and associations for mathematical concepts. But as Vygotsky (1986) argues, only when our sensory and experiential meanings are fused with linguistic meanings do 
we acquire the tools to express and use scientific concepts. Furthermore, the resultant semiotic tools that develop incorporate spoken language but also the full panoply of signs. Meanings are expressed through multimodal sets of signs including verbal sounds and spoken words, bodily gestures, arrangements of material objects, various markings, icons, pictures, written language and symbolic text. This echoes Mowat and Davis' (2010) identification of the multimodal sources of concept formation, discussed above. The difference is that I am not claiming that the learner is necessarily able to integrate these different modes of representation into a single overarching central concept. Although it is a longstanding shibboleth in mathematics education that experiences with structured concrete materials and manipulatives gives rise to abstract concepts, this is more an article of faith than a demonstrated finding. A number of researchers such as Hart (1989) have found that although scholars may see the structural or metaphorical connection between activities based on concrete representations and others using the abstract signs they are intended to represent, children often see these as two unrelated activities, with separate meanings and rules of procedure. Consequently learners too often fail to connect what are supposed to be different representations of the same concepts. This could be the outcome of poor instructional planning that does not highlight the links and shared structures. But it could also result from a deeper problem. Namely that offering the learner two representations with what is perceived by us to have a shared structure, especially where one is more abstract and the other more concrete, and expecting the learner to see the connection between them, may be to commit the fallacy of expecting learners to use the abstract concept they are in the process of constructing. Perhaps we cannot see a concrete situation as a metaphor for an abstract concept until the concept is already formed. If this is the case then there is a serious flaw in many uses of structural materials in teaching mathematics.

In addition, the assumption that bodily metaphors provide the foundations for subsequently more developed concepts is not without its critics. "Bachelard regards the common-sense mind's reliance on images as a breeding ground for epistemological obstacles ... [these] are often not explicitly formulated by those they constrain but rather operate at the level of implicit assumptions or cognitive or perceptual habits." (Gutting 1990: 135). Thus naïve notions like those derived from bodily metaphors may underpin misconceptions, such as the quasi-Aristotelian notions that Alternative Frameworks researchers in science education have documented extensively (Pfundt and Duit 1991).

One of the great strengths of the paper I am responding to is, however, that it suggests that mathematical knowledge, whether it be that of the learner, or of the culture of professional mathematics, is a growing, richly connected network or set of networks with many metaphors and links. Such networks have some central "hub" concepts or nodes, but are not organised hierarchically. This is a very rich metaphor for mathematics and for knowledge in general.

In contrast, I have implicitly foregrounded another metaphor: mathematics is language. This directs attention to further aspects of semiosis, including the tropes of metaphor and metonymy and their roles in making and extending meaning. Whichever route one takes, and it is by no means clear that these are inconsistent, it is evident that 
an exploration of metaphor and the metaphorical basis of mathematics is a very rich area, and that Mowat and Davis (2010) are commendably both opening up this discussion and provoking debate.

\section{References}

Browne, M. E. (2009). A sociocultural study of mathematical and other identities of "struggling" teenage boys, Unpublished Ed.D. Thesis, Exeter: University of Exeter Graduate School of Education. (Forthcoming in The Philosophy of Mathematics Education Journal No. 26, 2011, at http://people.exeter.ac.uk/PErnest/.)

Bruner, J. (1964). Towards a theory of instruction, Cambridge, Massachusetts: Harvard University Press.

Buerk, D. (1982). An experience with some able women who avoid mathematics, For the Learning Of Mathematics, 3(2), 19-24.

Deleuze, G. \& Guattari, F. (2007) A thousand plateaus: capitalism and schizophrenia, (B. Massumi, Trans.), Minneapolis, MN: University of Minnesota Press.

Ernest, P. (2006) A semiotic perspective of mathematical activity: the case of number, Educational Studies in Mathematics, 61, 67-101.

Ernest, P. (2008) Towards a semiotics of mathematical text (Part 2), For the Learning of Mathematics, 28(2), 39-47.

Gutting, G. (1990). Continental philosophy of and the history of science, in Olby, R. C. et al., Eds., Companion to the history of modern science, London, Routledge, 1990: 127- 147.

Hart, K. A. (1989). There is little connection, in Ernest, P. Ed. (1989) Mathematics teaching: The state of the art, London, Falmer Press.

Jakobson, R. (1956). Two aspects of language and two types of aphasic disturbances, in Jakobson, R. \& Halle, M., Fundamentals of language, The Hague: Mouton \& Company, 1956: 55-82.

Lakoff, G. \& Núñez, R (2000) Where mathematics comes from. New York, NY: Basic Books

Mowat, E. and Davis, B. (2010). Interpreting Embodied Mathematics using Network Theory: Implications for Mathematics Education, Complicity: An International Journal of Complexity and Education 7(1), 1-31.

Nuffield Mathematics Teaching Project (1965) I do and I understand (Draft edition), London: Nuffield Foundation.

Peirce, C. S. (1931-58). Collected papers (8 volumes), Cambridge, Massachusetts: Harvard University Press.

Pfundt, H. and Duit, R. (1991). Students alternative frameworks and science education Kiel, Germany: IPN, University of Kiel.

Vygotsky, L. S. (1986). Thought and language, (Translated. A. Kozulin) Cambridge, Massachusetts: Massachusetts Institute of Technology Press.

Wittgenstein, L. (1978). Remarks on the foundations of mathematics, Revised edition, Cambridge: MIT Press.

\footnotetext{
About the Author

Paul Ernest is emeritus professor of philosophy of mathematics education at Exeter University, UK and visiting professor in Oslo and Trondheim, Norway. His main research interests concern fundamental questions about the nature of mathematics and how it relates to teaching, learning and society. His best known publications are The Philosophy of Mathematics Education, Falmer 1991, and Social Constructivism as a Philosophy of Mathematics, SUNY Press, 1998. He founded and edits the Philosophy of Mathematics Education Journal, accessed via his web page at http://www.people.ex.ac.uk/ PErnest/
} 
PAUL ERNEST

(C) Copyright 2010. The author, PAUL ERNEST assigns to the University of Alberta and other educational and non-profit institutions a non-exclusive license to use this document for personal use and in courses of instruction provided that the article is used in full and this copyright statement is reproduced. The author also grants a non-exclusive license to the University of Alberta to publish this document in full on the World Wide Web, and for the document to be published on mirrors on the World Wide Web. Any other usage is prohibited without the express permission of the authors. 